\title{
THE RELIGIOUS DIMENSION OF ROGERS'S WORK
}

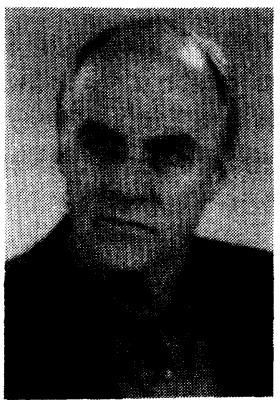

MARTIN A. VAN KALMTHOUT is an associate professor in the experiential approach to clinical psychology at Nijmegen University, the Netherlands, and is also in private practice as a personcentered therapist. He teaches introductory and advanced courses in psychotherapy, client-centered therapy, and the person-centered approach. His research interest in the history and foundations of psychotherapy in general and the person-centered approach in particular led to his book entitled Psychotherapie: Het Bos en de Bomen (Amersfoort, the Netherlands: Acco, 1991).

\section{Summary}

Carl Rogers can be considered one of the best examples of a proponent of a universal psychopathology and psychotherapy. His concept of the universal has a wider scope when he considers the actualizing tendency, which is operative in individual persons, to be part of a universal force that is operative not only in human beings but in all organic life all over the cosmos. This development of Rogers's thinking has been labeled "mystical universalism" and criticized as incompatible with his earlier emphasis on the unique individual person. In this article, the central question is whether Rogers's thinking in terms of the universal is indeed an aberration from his earlier philosophy or a logical and enriching newer development of the person-centered approach that deserves more attention. The author critically scrutinizes Rogers's concept of the universal and its relation to his view on the unique individual and discusses the implications and consequences of the results and conclusions thus obtained.

\section{INTRODUCTION}

In this article I explore Rogers's conceptualization of the universal and discuss some relevant questions that arise from this work.

Journal of Humanistic Psychology, Vol. 35 No. 4, Fall 1995 23-39

C 1995 Sage Publications, Inc. 
For instance, how is Rogers's view of the universal characteristics of human beings related to his philosophy of the unique individual person, and are they at all compatible with each other? Further, does Rogers's theory of the universal deserve more attention than it has received up until now, given that it may hold, as he stated himself many times, the fundamental core of his approach? Or should we say that Rogers's work on the universal in the last 10 years of his life led him to a serious departure from his earlier philosophy and even into "mystical universalism" (Van Belle, 1990)? If an alternative, more positive conclusion is to be reached, a difficult question arises, namely, how Rogers's elementary view of the universal might be further developed and how it is related to other similar philosophies, from not only psychological but also philosophical and religious origins. In other words, we then have to accept the possible religious dimension in Rogers's work and study it seriously. This might well be a step, however, that not many members of the person-centered community are prepared to take.

In preparing this article, I soon came to realize that I was asking very fundamental questions not only in regard to the personcentered approach but also concerning psychotherapy in general and life itself in its most fundamental processes. I therefore probably felt many of the same hesitations as other people who have had to undertake the journey into this unknown and perhaps dangerous field. First of all, the present subject leads one far beyond the field of psychotherapy into domains in which one may not be competent, such as philosophy and religious studies. Next, becoming aware of the enormity of the questions with which one is confronted, one is inclined to move to easier ones. Personally, I have felt, however, a strong urge to explore the subject matter of this article and I have learned, little by little during my life, that one should listen carefully to such urges, because they may indicate that it is worthwhile to take the risks involved, professionally and scientifically. Therefore, I take the freedom to present, though in a spirit of modesty, the following preliminary findings and reflections that I made during exploration of the religious dimension of Rogers's work.

\section{DEFINITIONS}

The first meaning of the concept of the universal to be discerned in Rogers's work is that of a "universal psychopathology" and a 
“universal psychotherapy.” By this I refer to Rogers's assumption that there is, in the end, only one problem and one therapy (Van Kalmthout \& Pelgrim, 1990). In Rogers's view, all human problems have as their basis the estrangement of human beings from their organismic valuing process, which brings about estrangement from their inner self, a not knowing who one really is. Given this universal psychopathology, Rogers argued in the same spirit that all human problems, whatever form they may have at the surface level, can be approached therapeutically by only one configuration, which is universally successful in every form of therapy. Thus his famous conditions for therapeutic personality change are considered the universal route for human beings to escape from fundamental estrangement and to discover who one really is.

Rogers used the concept of the universal in a much broader sense, however, especially when he used it to refer to characteristics that are common to not only all humanity but to all organic and even inorganic life, that is, to everything in the whole cosmos. The next quotation from $A$ Way of Being makes this quite clear:

There is another peculiar satisfaction in really hearing someone: It is like listening to the music of the spheres, because beyond the immediate message of the person, no matter what that might be, there is the universal. Hidden in all of the personal communications which I really hear there seem to be orderly psychological laws, aspects of the same order we find in the universe as a whole. So there is both the satisfaction of hearing this person and also the satisfaction of feeling one's self in touch with what is universally true. (Rogers, 1980, p. 8)

What is most interesting in this quotation is that Rogers links the universal to the personal. He seems to imply that the deeper one listens to a person or to oneself, the more one comes across something that is universally present in every person, representing some kind of basis or inner core of the individual. For Rogers, there seemed to be no real gap between the personal and the universal. He summarized this conviction in his well-known statement in On Becoming a Person: "What is most personal is most general (Rogers, 1961, p. 26).

Later in this article I shall return to this question of the relation between the personal and the universal. First, I will review the specific content given by Rogers to the universal. 


\section{THE ACTUALIZING TENDENCY}

As is well known, Rogers $(1959,1963)$ postulated rather early in his theoretical development the actualizing tendency as the only motive force in his theory of personality and psychotherapy. In his contribution to the Nebraska Symposium on Motivation, he stated:

So I would reaffirm, perhaps even more strongly after the passage of a decade, my belief that there is one central source of energy in the human organism; that it is a function of the whole organism rather than of some portion of it; and that it is perhaps best conceptualized as a tendency toward fulfillment, toward actualization, toward the maintenance and enhancement of the organism. (Rogers, 1963, p. 6)

One way to characterize this source of energy is by saying, "It is development towards autonomy and away from heteronomy, or control by external forces" (Rogers, 1959, p. 196). This means that its locus is internal, as opposed to external forces that might interfere with this inner source. It also implies that this force is unconscious rather than conscious, that it has more the character of "animal harmony" and is consistent with the idea that "man is wiser than his intellect." The synthetic concept given by Rogers for the quality of this source is "organismic," which once again stresses inner quality versus outer forces. The actualizing tendency, however, is not only the single force in individual organisms, it is also the motive force for the entire universe. In the latter case, Rogers (1978) called the actualizing tendency the "formative tendency."

\section{THE FORMATIVE TENDENCY}

In a chapter of $A$ Way of Being, entitled "The Foundations of a Person-Centered Approach," Rogers (1980) stated his theory of the formative tendency very strongly and made clear that this theory is very important to him, as it forms the foundation for the person-centered approach. In contrast to the actualizing tendency, which is a characteristic of organic life, the formative tendency is present at all levels of the cosmos, both inorganic and organic. In a summary formulation, Rogers says:

I hypothesize that there is a formative directional tendency in the universe, which can be traced and observed in stellar space, in crystals, in micro-organisms, in more complex organic life, and in 
human beings. This is an evolutionary tendency toward greater order, greater complexity, greater interrelatedness. In humankind, this tendency exhibits itself as the individual moves from a singlecell origin to complex organic functioning, to knowing and sensing below the level of consciousness, to a conscious awareness of the organism and the external world, to a transcendent awareness of the harmony and unity of the cosmic system, including humankind. (p. 133)

The concepts of the actualizing and formative tendency form the foundations for the person-centered approach because they are the justification for "engaging in a life-affirming way of being" (p. 134). If one, as a therapist or just as a human being, is able to create the climate in which people are able and willing to be themselves, one is "tapping into a tendency which permeates all organic life" (p. 134) and "tuning in to a potent creative tendency which has formed our universe" (p. 134). In such a case, "consciousness is participating in this larger, creative, formative tendency" (p. 128). What also happens then is that two persons in such a climate or state of consciousness have contact with each other on a very deep level, so that the inner spirit of the one touches the inner spirit of the other. These persons are in such cases close to their "inner, transcendental core" and feel part of the broader, universal consciousness or feel one with the universal. As Rogers put it, this reminds one of the mystic's experience of "union with the universal" (p. 128).

One other implication of Rogers's (1964) theory is that it implies universality of values, or what he called "an organismic commonality of value directions." These value directions are universal in the sense that they are not culture-bound, but rather are "due to the fact that we all belong to the same species" (p. 166). In Rogers's summary of his view, it becomes clear once more why he considered his theory of the formative tendency basic to his approach to therapy and interpersonal relationships:

Instead of universal values "out there", or a universal value system imposed by some group-philosophers, rulers, priests, or psychologists - we have the possibility of universal human value directions emerging from the experiencing of the human organism. Evidence from therapy indicates that both personal and social values emerge as natural, and experienced, when the individual is close to his own organismic valuing process. The suggestion is that though modern man no longer trusts religion or science or philosophy nor any system of beliefs to give him values, he may find an organismic valuing base within himself which, if he can learn again to be in 
touch with it, will prove to be an organized, adaptive, and social approach to the perplexing value issues which face all of us. (p. 167)

For our purposes, a core formulation in the above quotation appears to be "an organismic valuing base within himself." In that formulation, Rogers indicated once again that, in his view, each individual person has within himself a source that is universal and at the same time very personal.

\section{MYSTICAL UNIVERSALISM?}

How is one to appreciate Rogers's theory of the universal oneness of all things and all organisms? One understandable criticism might be that this theory moves away from the concrete reality of individual clients in therapy and their problems toward a metaphysical, religious, and mystical creed. An implication of that would be that the person-centered approach thus moves in a direction that is incompatible with its own philosophy, in which the individual experience of the unique person is the only authority. This view is put forward by Van Belle (1990), who has criticized Rogers rather heavily for his, what he calls, "later move towards mysticism." On the one hand, Van Belle is convinced that Rogers's thinking in his later years is a logical consequence of his basic philosophy, in which the growth-principle is more important than his regard of the individual person and in which process, rather than any kind of structure, is the core concept in his theory of personality (Van Belle, 1980). On the other hand, however, he considers Rogers's latter development, as understandable as it might be from his "basic intent," a departure from third-force humanistic psychology and a move into fourth-force transpersonal psychology. In his view, here was coming an end to Rogers's earlier role as the defender of individual persons and Van Belle even wonders whether Rogers's universalism is really different from the worldavoiding fundamentalist view of Rogers's own parents, a view he abandoned as a youth, and whether he thus was becoming any less reductionist than Skinner. These are serious accusations indeed!

A more positive attitude toward Rogers's universalism is taken by Bozarth (1985) and Sanford (1993), who link Rogers's theory of the formative, directional tendency to general systems theory, modern physics, the views of mystics, and to Eastern religious thought. In their opinion, all of these approaches can contribute to 
a better understanding of the basic philosophy underlying the person-centered approach.

I would tend to say, at this point, that it is not a necessary conclusion that Rogers in his later years moved into "mystical universalism." I do understand that Rogers's reference to mystical experiences and paranormal phenomena to many people, within the person-centered approach as well as outside it, is repugnant and even unacceptable. It seems to me that Rogers was exploring a serious dimension of his approach, which raises a number of questions, however. To put it differently, Rogers appears to have touched at the end of his life upon a further logical consequence of his approach, which he was unable, for several reasons, to develop or crystallize fully. Therefore, much of this later development remains obscure and needs further clarification, not rejection.

What is clear to me about Rogers's theory of the universal thus far is that in contrast to the outer forces that bring about estrangement, there is the inner source of the living organism. This inner force is present in all organic and inorganic life and, as far as the individual person is concerned, estrangement can be wiped away by taking part in this cosmic life force. To help people to live in that force is the purpose of therapy. The assumption that such a universal, creative, and positive source of energy exists is the foundation for a fundamentally affirmative approach to life, to therapy, and to interpersonal relationships in general.

In the following, I will explore some of the questions that arise from Rogers's thinking about the universal.

\section{THE QUALITY OF THE INNER SOURCE}

First of all, I would like to try to clarify, as far as possible, the quality of the inner source to which Rogers made reference.

Generally speaking, Rogers was referring to two different worlds in which we live. In his concepts, these worlds can be designated as "the inner world of the organismic valuing process" and "the outer world of the conditions of worth." For some, the first one could well be characterized as "religious," as it is considered by Rogers to be the ground of all life and its unifying force. It is important to notice, however, that he was talking here about exclusively human experiences, not about something "out-there," something from the "spiritual world" that is different from our 
human world in which we live. For that reason, the qualification of the inner source as religious could well be a complete misinterpretation of what really moved Rogers (O'Hara, 1987). I will return to this issue later.

A more appropriate interpretation of Rogers's work on the universal might be that he, like many natural scientists, was fascinated with the laws of nature and "like the mystic ... is fired by a desire to come ever closer to a direct experience of this lawfulness or harmony" (O'Hara, 1987, p. 3). This is most clearly expressed by Rogers in the famous passage on the universal, quoted in the Definitions section of this article. What is most conspicuous in that quotation, however, is that Rogers considered the personal communications with another person as the gate to these universal laws. This is not that unexpected if we realize that Rogers's general theory is founded on two pillars, namely, (a) the process of experiencing reality as it is (which is the organismic life flow) and (b) the conditions that make this possible, that is, the core therapeutic conditions. This means that for Rogers the deep personal communication with another human being brings one in contact with what is universally true for all humanity. As far as the quality of the inner source is concerned, this means that this quality is related to what traditionally has been called "the search for truth" (experiencing reality as it is) and "love" (assuming that this rather misused word describes the essence of the core conditions; Brazier, 1993). This means that the essential quality of the inner source can only be experienced through the highest human interpersonal capacities (summarized as love). For Rogers, these interpersonal relations are like a window to the experiencing of reality. These relationships (as defined by him) are the necessary and sufficient conditions for the experiencing of the organismic life flow (as Rogers defined "reality").

It seems to me that Rogers must have been aware of the absolute character of what he considered the essentials of his approach and that he was in search of a solid foundation for it. He himself would be the first to state that in this search, much work has yet to be done. There is another reason, however, why we should be modest in making further assertions about the quality of the inner source, which is what William James (1902/1977) calls its ineffability. This quality follows directly from its utter personal-experiential character, which makes all verbalizations secondhand to the primary experience of the inner source. 


\section{THE RELATION BETWEEN}

\section{THE PERSONAL AND THE UNIVERSAL}

Now I would like to elaborate on whether Rogers's universalism is incompatible with his emphasis on the unique individual person. This possible discrepancy arises from the observation that Rogers was not altogether very clear about what he meant by the self. Sometimes he tended to confuse self and self-concept (Roberts, 1985). In other places he so emphasized process rather than structure, change and flux more than personality or identity, that one gets the impression that he seemed never to refer to a static entity or structure within the person, but merely to the concept of self, which, at least in a healthy person, is as changing as the organismic process itself (Van Belle, 1980). To put it differently, "becoming myself" seems then to have meant to Rogers "becoming the organismic process," instead of "becoming a separate individual." This implies in fact that the self is then more an impediment to growth and change than a help. In its most extreme consequence, this view even implies that the self has to die to permit the organismic life to develop fully. This means that, paradoxically enough, "by giving up, one gains control," as Van Belle summarized it.

How can we understand this latter statement? A participant in one of Rogers's workshops did not feel any discrepancy between the experiencing of the personal and the universal consciousness. She says:

I found it to be a profound spiritual experience. I felt the oneness of spirit in the community. We breathed together, felt together, even spoke for one another. I felt the power of the "life force" that infuses each of us-whatever that is. I felt its presence without the usual barricades of "me-ness" or "you-ness" - it was like a meditative experience when I feel myself as a center of consciousness, very much a part of the broader, universal consciousness. And yet with that extraordinary sense of oneness, the separateness of each person present has never been more clearly preserved. (Rogers, 1980, pp. 129-130)

Within the framework of Rogers's theory, we could explain this paradox as follows. Individual persons have lost their inner strength through their living in the world of the "conditions of worth." Their life is governed by their self-concept (negative and/or ideal), which is entirely a product of the conditions of worth, that is, a product of external forces. In this view, change essentially 
means moving from this outer world into the inner world of the organismic life flow. It logically implies the dying of the self (which is the self-concept), permitting the organism to come to life. The dying of the old self, therefore, is the necessary condition for the new life to come into being. Although this transformation may be difficult and painful, it brings the person enormous strength and energy, contrary to the exhausted old self. The latter had more the character of "dead, while living."

So there is no contradiction between the personal and the universal, because they both refer to the inner world of the organismic life force, in contrast to the outer world that is inhabited by "selves" who are estranged from this inner source and, paradoxically, can thus not "be themselves." This is why people experience the inner source as their most personal inner core and feel then "to be that self which one truly is" (Rogers, 1961 [1977], p. 166). The paradoxical thing, however, is that in this most personal inner core people get the feeling of universality that in group psychotherapy has been described as the "welcome to the human race experience" and as the feeling of "we are all in the same boat" (Yalom, 1975). As indicated in the citation above from one of Rogers's, workshops the "me-ness" and "you-ness" (which is the conditioned self, or selfconcept or personality) no longer form a barrier to the experiencing of a deeper sense of personhood, which is common to all humanity. It refers to a basic human experience of a sense of universality in which an individual human being feels connected with all humanity.

As this feeling of being connected to the whole might well be the hard core of many philosophical and religious traditions, it is understandable that Rogers, though to his own surprise, discovered the similarities between these traditions and his own work and referred to them (e.g., in one of the chapters of $A$ Way of Being, he refers to Buddhism, Zen, and Lao-tse; pp. 41-42).

IS ROGERS'S THINKING ABOUT THE UNIVERSAL TO BE QUALIFIED AS RELIGIOUS?

One author who may be of help in answering this question is William James (1902/1977), who made in his famous book The Varieties of Religious Experience a distinction between institutional and personal religion. The latter, in contrast to the former, stresses 
the experiential nature of religion, which means that its focus is religious experiences rather than dogmas, rituals, churches, sects, and their indoctrinations. James used the term second-hand to indicate the institutional type of religion. He also emphasized the importance of feelings and their here-and-now quality. In short, he accentuated the experiential character of religious and mystical states. There can be no doubt that Rogers too, in his later work, was talking about personal, individual, and inner experiences, which had no bearing whatsoever on a dogmatic, institutional, and authoritative creed (i.e., imposed from outside). More precisely, James defined religion in this sense as follows: "The feelings, acts, and experiences of individual men in their solitude, so far as they apprehend themselves to stand in relation to whatever they may consider the divine" (p. 51).

Fuller (1984) stated already some years ago that the philosophical and metaphysical assumptions of Rogers's approach are of a true religious quality, religion being defined as "personal, experiential religion," as it was by James.

O'Hara (1987), on the other hand, is of the opinion that the term religious would be inappropriate in Rogers's case, because "He was first, last and always a seeker, a questioner, a learner" (p. 2). According to her, Rogers could be qualified as "a mystic-albeit an antireligious one." That means that he was fundamentally opposed to religious systems but was a mystic in the sense that he believed in the lawfulness of the universe and that he, "like the mystics, acknowledged no greater authority than his own experience" (p. 4). What O'Hara seems to say is that organized religion was something foreign to Rogers, but that he appreciated what has been called religious experience in the sense of the mystical tradition (Deikman, 1982).

Thorne (1990) has suggested that Rogers was only in the last 10 years of his life referring to the "spiritual" and the "mystical," because "until the end of his life [Rogers] had borne the scars of wounds inflicted upon him by a perverse and primitive theology" (p. 396). I am sure that what might be true for Rogers has also been true for many client-centered and other psychotherapists of his generation. This might well explain why up till now religion and related topics have received a very critical, if not prejudiced, treatment by psychotherapists of all schools (Bergin, 1980). I do not think, however, that Rogers's approach would be helped by studying theology or by intermingling it with Christianity or any 
other organized religion or system of belief. What would be helpful is a scientific and objective study and exploration of the possible "religious" dimension of Rogers's work, not blocked by personal, professional, or academic prejudices.

There is no doubt, however, that for many members of the person-centered community, such a perspective is still very unattractive. It should be noted, though, that the person-centered approach can never be a vehicle for any institutional religion, and that any linkage to churches, sects, and so forth has the danger of being incompatible with the person-centered approach's experiential character. It is very important to realize in this context that the person-centered approach is directed at the experiencing of life in all its dimensions. As Rogers (1951) stated: "Therapy is of the essence of life, and is to be so understood" (p.x). This "way of being" is utterly incompatible with any dogmatic or ritualistic approach to life, including attempts to make the person-centered approach itself a system of belief, instead of an experiential, open approach to life. Elaborating on James's distinction between personal and institutional religion, it might well be useful to make here the distinction between personal and institutional psychotherapy. Rogers was, for good reasons, always very hesitant at organizing his approach, because he was very well aware that an institutionalized form of psychotherapy inevitably is a threat to personal experience.

As a conclusion and an answer to the question of this section, I would like to state the following: Rogers's thinking about the universal could well be qualified as religious in the sense of mystical or religious experience, not at all in the sense of organized religion. His approach to this dimension might, following O'Hara (1987), best be qualified as that of an antireligious mystic, one that is not uncommon among natural scientists, like for example Einstein and Bohm (1981). Because of the ambiguous meaning of the word religious, it would be better to avoid that concept, without denying the fact that Rogers's approach has a true religious dimension in it and asks typical religious questions. This also implies that Rogers's approach is not first of all to be considered a system of techniques but a way of being that includes a system of values, among other things. A good qualification of this approach would be what Kurtz (1986) calls "a secular humanism." Kurtz's article of faith regarding secular humanism is also a good qualification for Rogers's explorations of the universal: 
Secular humanism provides an outlook on man and the universe, a philosophy of life, an ethic of reason and freedom. It is the story of possibility and outreach. Secular humanism is an alternative to the religions of illusion and salvation. But how it copes with the claims of the transcendent without dogmatically dismissing them and how it deals with life, offering opportunity and power, is a crucial issue. Can secular humanism provide a meaningful substitute for God and the transcendent? Can it deal with the world as it is and yet help us to fulfill our basic yearnings and hopes for what we might become? (Kurtz, 1986, p. xiv)

\section{CONCLUSION AND DISCUSSION}

In this article, I have reviewed Rogers's concept of the universal by examining his concepts of the actualizing tendency and the universal formative tendency. Next, I paid attention to the view that Rogers moved toward mysticism in his later years. Three questions emerged from this review: (1) What is the quality of the inner source? (2) What is the relationship between the personal and the universal? (3) Is Rogers's thinking about the universal to be qualified as religious?

In regard to the first question, it was concluded that Rogers's theory in its fundamental assumptions has a true religious quality. As to the second question raised, I concluded that no essential contradiction exists between the personal and the universal, because both refer to the inner source where the personal and the universal meet. In regard to the third question, it was concluded that the qualification religious furthers misunderstanding, because of the ambiguous meaning of that word.

The present review raises some fundamental and unresolved issues in Rogers's theory that, I think, need further study. The first one pertains to the concept of the self. I think that Rogers's theory does not elucidate whether he assumes a self as a separate identity (as he certainly did in the early phases of his thinking) or sees the self as merely a self-concept that has no structure at all but is merely "changingness" (as he emphasized in his later years). In a popular way, the expression "to be oneself" has been used widely and has even been misused because many people have not been too aware of the ambiguity of this expression. Does it mean, for instance, to do whatever one likes, without awareness of the conditions of one's preferences? In other words, how does one know 
whether one is not still within the field of the "conditions of worth" instead of taking part in the universal organismic life flow? This popular usage has also seriously neglected the overwhelming evidence on the conditioned quality of the human being. Rogers seems to have been aware of this, as evidenced by his emphasizing the relativity of the self as a concept versus the unconditioned quality of the organism. What he was not able to do was to clarify the quality of the universal order as it is present in the individual person. As is well known, the discussion about the character of the self has led to disagreement between humanists on the one hand and behaviorists and psychoanalysts on the other, but it has also led to disagreement between humanists and existentialists and transpersonal psychologists (Rowan, 1989). Relevant for the present context is whether the emphasis on the autonomous and unique self is itself an illusion that has serious and debatable consequences (O’Hara, 1989; Wilber, 1989). It seems quite clear to me that in emphasizing the importance of autonomy, the other side of the coin, namely belongingness, has been greatly neglected (see Angyal, 1965; O'Hara, 1984).

The second issue in regard to Rogers's theory is whether his concept of the universal refers to "another reality," and what the quality of this reality is. We said earlier that, in Rogers's approach, a dichotomy is made between the inner world of the organismic life force and the world of the outer forces of the conditions of worth. It seems to me that this distinction is very meaningful, but that further study is necessary to clarify the respective qualities of these two worlds. It also seems necessary to avoid in this study all kinds of illusory metaphysics and to remain as factual, critical, and scientific as possible. One good example of such an approach, which may be interesting to apply to Rogers's theory, is the theory of theoretical physicist David Bohm (1981) on the "implicate" and "explicate" order, based on a thorough analysis and critic of quantum theory and the theory of relativity. One could ask, for instance, whether the explicate order is related to what Rogers designates as "the world of the conditions of worth" and whether the implicate order might elucidate what Rogers calls the "organismic life flow." Such an approach demonstrates that it is possible to delve into the most fundamental (if you like, religious) questions regarding the ultimate reality, without "going metaphysical."

A final issue pertains to the relation in Rogers's theory between science, religion, philosophy, the arts, and so forth. From the 
foregoing, it seems inevitable that the person-centered approach should not take its inspiration from science alone. This demands, in the first place, a broad view of what science is. As is well known, Rogers was convinced that the normal scientific approach had limitations, and he was therefore in search of viable alternatives (Rogers, 1985), as were his followers (Seeman, 1990). But next, the question is how sources other than the scientific can be used in a way that is acceptable to the scientific community (O'Hara, 1987). Here the limitations not only of science but also of psychotherapy, of religious systems, in fact of all human thinking, are at stake. As regards the person-centered approach, this need not be a problem at all, because the highest authority has never been science or other knowledge but the experience of reality, whether we call such experience religious, scientific, artistic, or otherwise.

It seems to me that Rogers in his later days had sensed the importance of the concept of the universal for the foundations of the person-centered approach, without having been able to see all the implications of it and without having been able to work out a number of unsolved questions. This, of course, is no problem at all within an approach where process rather than structure is the end. It is therefore up to those of us who are convinced of the importance of Rogers's later development to carry forward this work.

\section{REFERENCES}

Angyal, A. (1965). Neurosis and treatment. New York: Wiley.

Bergin, A. (1980). Psychotherapy and religious values. Journal of Consulting and Clinical Psychology, 48, 95-105.

Bohm, D. (1981). Wholeness and the implicate order. London: Routledge \& Kegan.

Bozarth, J. D. (1985). Quantum theory and the person-centered approach. Journal of Counseling and Development, 64, 179-182.

Brazier, D. (1993). The necessary condition is love: Going beyond self in the person-centered approach. In D. Brazier (Ed.), Beyond Carl Rogers. Towards a psychotherapy of the twenty-first century (pp. 72-91). London: Constable.

Deikman, A. (1982). The observing self: Mysticism and psychotherapy. Boston: Beacon.

Fuller, R. C. (1984). Rogers' impact on pastoral counseling and contemporary religious reflection. In R. F. Levant \& J. M. Shlien (Eds.), Clientcentered therapy and the person-centered approach: New directions in theory, research, and practice (pp. 352-369). New York: Praeger. 
James, W. (1977). The varieties of religious experience. Glasgow, Scotland: Fount Paperbacks. (Original work published 1902)

Kurtz, P. (1986). The transcendental temptation. New York: Prometheus.

O'Hara, M. (1984). Person-centered Gestalt: Toward a holistic synthesis. In R. Levant \& J. Shlien (Eds.), Client-centered therapy and the personcentered approach: New directions in theory, research, and practice (pp. 203-221). New York: Praeger.

O'Hara, M. (1987, November 7). Carl Rogers: Scientist and mystic. Paper presented at UCLA Extension in memorial honor of Carl Rogers, Los Angeles, CA.

O'Hara, M. (1989). When I use the term humanistic psychology . . . Journal of Humanistic Psychology, 29(2), 263-273.

Roberts, R. (1985a). Carl Rogers's quiet revolution: Therapy for the saints. Does "empathy" equal Christian love? Christianity Today, 29(16), 25-28.

Roberts, R. (1985b). Carl Rogers and the Christian virtues. Journal of Psychology and Theology, 13(4), 263-273.

Rogers, C. R. (1951). Client-centered therapy: Its current practice, implication, and theory. Boston: Houghton Mifflin.

Rogers, C. R. (1959). A theory of therapy, personality and interpersonal relationships, as developed in the client-centered framework. In S. Koch (Ed.), Psychology: A study of a science (pp. 184-256). New York: McGraw-Hill.

Rogers, C. R. (1963). The actualizing tendency in relation to "motives" and to consciousness. In M. Jones (Ed.), Nebraska symposium on motivation (pp. 1-24). Lincoln: University of Nebraska Press.

Rogers, C. R. (1964). Toward a modern approach to values: The valuing process in the mature person. Journal of Abnormal and Social Psychology, 68, 160-167.

Rogers, C. R. (1977). On becoming a person. London: Constable. (Original work published 1961)

Rogers, C. R. (1978). The formative tendency. Journal of Humanistic Psychology, 18(4), 23-26.

Rogers, C. R. (1980). A way of being. Boston: Houghton Mifflin.

Rogers, C. R. (1985). Toward a more human science of the person. Journal of Humanistic Psychology, 25(4), 7-24.

Rowan, J. (1989). Two humanistic psychologies or one? Journal of Humanistic Psychology, 29(2), 224-229.

Sanford, R. (1993). The theory of the person-centered approach and the theory of chaos: From Rogers to Gleick and back again. In D. Brazier (Ed.), Beyond Carl Rogers. Towards a psychotherapy of the twenty-first century. London: Constable.

Seeman, J. (Ed.). (1990). Human inquiry and the person-centered approach [special issue]. Person-Centered Review, 5 .

Thorne, B. (1990). Carl Rogers and the doctrine of original sin. PersonCentered Review, 5, 394-405.

Van Belle, H. A. (1980). Basic intent and therapeutic approach of Carl $R$. Rogers. Toronto, Canada: Wedge. 
Van Belle, H. A. (1990). Rogers's later move toward mysticism: Implications for person-centered therapy. In G. Lietaer, J. Rombauts, \& R. Van Balen (Eds.), Client-centered and experiential psychotherapy in the nineties (pp. 47-57). Leuven, Belgium: Leuven University Press.

Van Kalmthout, M. A., \& Pelgrim, F. A. (1990). In search of universal concepts in psychopathology and psychotherapy. In G. Lietaer, J. Rombauts, \& R. Van Balen (Eds.), Client-centered and experiential psychotherapy in the nineties (pp. 381-396). Leuven, Belgium: Leuven University Press.

Wilber, K. (1989). Two humanistic psychologies? A response. Journal of Humanistic Psychology, 29(2), 230-243.

Yalom, I. (1975). The theory and practice of group psychotherapy (2nd ed.). New York: Basic Books.

Reprint requests: Martin Van Kalmthout, Postbus 9104, 6500 HE Nijmegen, the Netherlands. 